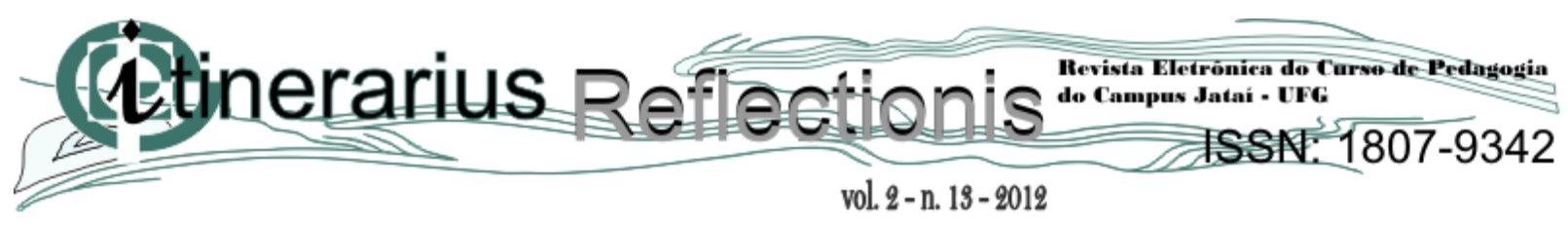

\title{
ANÁLISE DE CONCEPÇÃO AMBIENTAL DOS ALUNOS DOS CURSOS INTEGRADOS DO IFG CÂMPUS JATAÍ
}

\author{
Kenia Alves Pereira Lacerda - Instituto Federal de \\ Goiás, Câmpus Jataí - keniaapl@bol.com.br
}

Silvio Lacerda de Oliveira - Centro de Ensino Superior de Jataí - CESUT, Jataí

\begin{abstract}
RESUMO: A falta de conscientização do ser humano sobre as consequencias de seus atos, principalmente em relação ao ambiente que vive, contribui sobremaneira para a degradação ambiental acelerada. $\mathrm{O}$ desperdício e mal uso dos recursos naturais, o errado descarte de lixo e outros resíduos, o aumento de gases emitidos para a atmosfera e o desmatamento descontrolado são apenas alguns exemplos de desenvolvimento insustentável (SALEM, 2005). A educação ambiental é uma das ferramentas existentes para a sensibilização e capacitação da população em geral sobre os problemas ambientais. Com ela, busca-se desenvolver técnicas e métodos que facilitem o processo de tomada de consciência sobre a gravidade dos problemas ambientais e a necessidade urgente de debruçar seriamente sobre eles (MARCATTO, 2006). Dessa forma, o objetivo desta pesquisa foi avaliar a concepção ambiental dos alunos dos cursos integrados que cursam os primeiros anos de eletrotécnica e edificações, do IFG Campus Jataí. Visando contribuir para a formação de cidadãos conscientes, aptos para decidir e atuar na realidade socioambiental de um modo comprometido com a vida. A investigação evidenciou que os alunos, de uma forma geral, apresentam ainda uma visão preservacionista e conservacionista sobre o meio ambiente e conceito incipiente sobre educação ambiental. Sabe-se que o termo meio ambiente e educação ambiental estão presentes nos currículos pedagógicos, portanto, é um desafio para professores abordarem e desenvolverem tais termos em sala de aula.
\end{abstract}

Palavras-chave: Concepção ambiental. Educação ambiental. Visão preservacionista.

\begin{abstract}
The lack of awareness of the human being on the consequences of his/her acts,mainly in relation to the environment that lives, may contribute, greatly, to the acelerated degradation of the environment. The waste and the badly use of natural resources, the inadequate disposal of garbage and other residues discharging,an expressive increase of gases emitted into the atmosphere, and the uncontrolled deforestation are only some examples of an unsustainable development (SALEM, 2005). The environmental education is one of the existent tools to the sensibilization and capacitation of population in general about the environment problems. With it, it is attempted to develop techniques and methods, which might facilitate a genuine awareness, concerning about the gravity of environmental problems and the urgent need to, seriously, deal with them (MARCATTO, 2006). So, the aim of this research was at evaluating the environmental conception of the students, who are doing the earlier years of Eletrotechnology and Civil Engineering Technician integrated courses. Aiming at contributing to form conscious citizens, capable to decide and act in the socio-
\end{abstract}




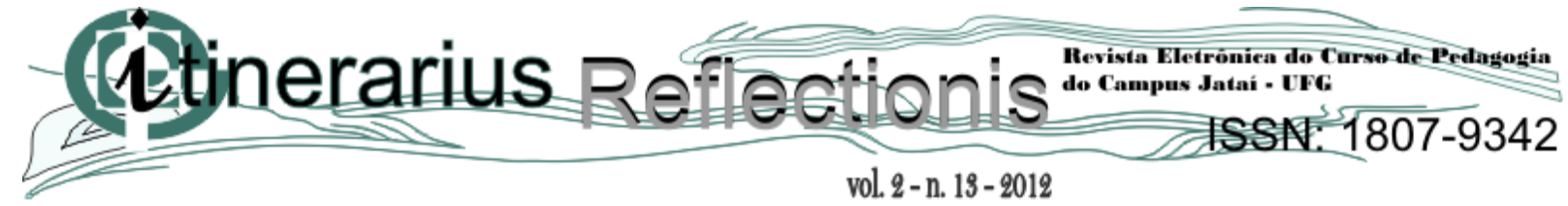

environmental reality, deeply compromised by issues linked to preservation of life itself. This investigation uncovered that the students, in general, still present a preservationist and conservationist view about the environment and an incipient conception about environmental education. It is known that the environment and environmental education terms can be found in the pedagogic curricula. However, it is a challenge for teachers to approach and develop those terms in the classroom.

Key-words: Environmental conception. Environmental education. Preservationist view.

\section{Introdução}

Vivemos numa época de grandes transformações sociais, econômicas, políticas e ambientais, que nem sempre são positivas. Juntamente com os progressos técnico-científicos convive-se com a degradação da vida humana e dos valores sociais e individuais (LOPES, NETO, SANTOS, 2007). Diante disso, vêm intensificando as preocupações inerentes à temática ambiental e, concomitantemente, as iniciativas dos variados setores da sociedade para o desenvolvimento de atividades, projetos e congêneres no intuito de educar as comunidades, procurando sensibilizá-las para as questões ambientais, e mobilizá-las para a modificação de atitudes nocivas e a apropriação de posturas benéficas ao equilíbrio ambiental (RUY, 2004).

A educação ambiental é uma das ferramentas existentes para a sensibilização e capacitação da população em geral sobre os problemas ambientais. Com ela, busca-se desenvolver técnicas e métodos que facilitem o processo de tomada de consciência sobre a gravidade dos problemas ambientais e a necessidade urgente de debruçar seriamente sobre eles (MARCATTO, 2006).

Segundo Vasconcelos (2000), a presença, em todas as práticas educativas, da reflexão sobre as relações dos seres entre si, do ser humano com ele mesmo e do ser humano com seus semelhantes é condição imprescindível para que a Educação Ambiental (EA) ocorra. O tratado de educação ambiental para sociedades sustentáveis e responsabilidade 
global, elaborado na Conferência das Nações Unidas para o Meio Ambiente e desenvolvimento (Uniced/92), mais conhecido como Rio 92, definiu educação ambiental como um processo de aprendizagem permanente, baseado no respeito a todas as formas de vida. Tal educação afirma valores e ações que contribuem para a transformação humana e social e para a preservação ecológica. Ela estimula a formação de sociedades socialmente justas e ecologicamente equilibradas, que conservam entre si relação de interdependência e diversidade. Isto requer responsabilidade individual e coletiva em nível local, nacional e planetário.

Nesse contexto, sobressaem-se as escolas, como espaços privilegiados na implementação de atividades que propiciem essa reflexão, com ações orientadas em projetos e em processos de participação que levem à autoconfiança, a atitudes positivas e ao comprometimento pessoal com a proteção ambiental implementados de modo interdisciplinar (DIAS, 1992).

Esse processo de sensibilização da comunidade escolar pode fomentar iniciativas que transcendam o ambiente escolar, atingindo tanto o bairro no qual a escola está inserida como comunidades mais afastadas nas quais residam alunos, professores e funcionários, potenciais multiplicadores de informações e atividades relacionadas à Educação Ambiental na escola. Souza (2000), afirma inclusive, que o estreitamento das relações intra e extra-escolar é bastante útil na conservação do ambiente, principalmente no ambiente escolar. Segundo Dias (1992), a EA na escola deve ter como objetivos a sensibilização e a conscientização, objetivando a proteção ambiental em harmonia com o desenvolvimento sustentado.

Na educação ambiental contemporânea, percebemos um grande esforço em se alcançar a eficiência em alfabetização ambiental, esquecendo-se da questão básica, que é o aspecto afetivo da relação. Como afirma Travassos (2004), não basta tornar os alunos ecologicamente alfabetizados, é preciso fazê-los portadores de um sentimento de compromisso com a preservação da vida em todas as suas formas, dom indissociável da garantia do ambiente que lhe seja propício.

A EA preocupa-se com a sociedade e sua interação com a natureza, nos ensinos formal, não-formal ou informal. O ensino formal é um processo institucionalizado que ocorre 


\section{(1itinerarius \\ vol. 2-n. 13-2012 \\ Revista Eletróniéa do Curse de Pedagogia

nas unidades de ensino, públicas e privado, englobando educação básica, também na educação superior, na educação especial, na educação profissional e na educação de jovens e adultos. Já a educação não-formal ou informal, são vistas como ações e práticas educativas voltadas à sensibilização da coletividade sobre as questões ambientais e à sua organização e participação na defesa da qualidade do meio ambiente. Entende-se que há caracterização por sua realização fora da escola, envolvendo flexibilidade de métodos e de conteúdos e um público alvo muito variável em suas características: faixa etária, nível de escolaridade, nível de conhecimento da problemática ambiental, entre outros aspectos (CASTRO, 2004). Mas, a EA carece de princípios, metodologias e conteúdos que possam estar articulados com a quantidade infindável de temas que devem aos olhos das demandas sócio-ambientais, integrarem sua prática (SAHED, ASIMELLI-LUZ 2006).

O ensino, formal e informal, refere-se aos espaços amplos conquistados pela ação da educação ambiental, como representa uma nova dimensão que vem sendo incorporada ao currículo escolar de forma transversal e interdisciplinar, professores, alunos, e todas as pessoas envolvidas no processo ensino-aprendizagem, necessitam desenvolver ações concretas, no sentido de mudarem suas relações com o ambiente. Isto bem prescreve os Parâmetros Curriculares Nacionais (PCNs):

a principal função do trabalho com meio ambiente é contribuir para a formação de cidadãos conscientes, aptos a decidir e atuar na realidade socioambiental de um modo comprometido com a vida, com o bem estar de cada um e da sociedade, local e global. Para isso, é necessário que, mais do que informações e conceitos, a escola se proponha a trabalhar com atitudes, com formação de valores, com ensino-aprendizagem de procedimentos (BRASIL, 2001, v. 9 p.29).

Sendo assim, a questão ambiental vem sendo considerada como cada vez mais urgente para a sociedade, pois o futuro da humanidade depende da relação estabelecida entre a natureza e o uso pelo homem dos recursos naturais. Segundo Dias (2002), essa relação desequilibrou a sustentabilidade ecológica o que traz graves consequências para a qualidade de vida dos sujeitos sociais. $\mathrm{O}$ autor afirma também que o modelo de desenvolvimento econômico adotado em nosso país, por um lado gera opulência, por outro, gera exclusão 


\section{(titinerarius Reffectionis 20 \\ vol. 2-n. 13-2012}

social e crise de percepção ambiental, e ambos degradam. Para manter-se o atual estilo de vida, destroem os sistemas de suporte da vida na terra. A falta de conscientização e respeito do ser humano contribui sobremaneira para a degradação ambiental acelerada. O desperdício e mau uso dos recursos naturais, o errado descarte de lixo e outros resíduos, o aumento de gases emitidos para a atmosfera e o desmatamento descontrolado são apenas alguns exemplos de desenvolvimento insustentável. Segundo a associação dos catadores de material reaproveitável (ASMARE), 64\% dos municípios brasileiros destinam seus resíduos sem tratamento a lixões ou a cursos de água e em $20 \%$ dos domicílios brasileiros, o lixo nem chega a ser coletado. A maioria dos brasileiros não sabe para onde os resíduos são destinados e o que acontecerá com eles. Os diversos aterros sanitários e lixões hoje existentes no país já estão com suas capacidades esgotadas (SALEM, 2005).

Um dos problemas do lixo está justamente na sua elevada produção, representando um grande desperdício de recursos naturais. Uma possível alternativa para esse problema é o uso racional dos bens de consumo, a fim de reduzir a produção de resíduos sólidos (OLIVEIRA, 2003). Nesse sentido, é fundamental que haja uma mudança de hábito de consumo da população para diminuir a quantidade de lixo produzido e, conseqüentemente, os seus efeitos ambientais, uma vez que eles demandam muito tempo para se decompor (BARBOSA, 2002).

O grande obstáculo a essa redução está no fato de que somos consumidores, fazemos parte de uma sociedade cada vez mais industrializada, onde há um grande passivo ambiental, na forma de lixo produzido. Sato (2000) salienta que a EA não se limita, entretanto, a atitudes singulares e muito menos a ações pontuais, o mesmo é contra o ativismo puro ou o teoricismo sem prática.

Para reduzir a produção de lixo, há necessidade de uma mudança de atitude no que diz respeito aos hábitos de consumo. Logo, é preciso evitar os supérfluos e o desperdício, além de usar os descartáveis somente quando for imprescindível. A reutilização do lixo, objetivando a preservação ambiental, o incentivo à coleta seletiva e a reciclagem de diversos tipos de material já vêm sendo adotados nas principais sociedades. 


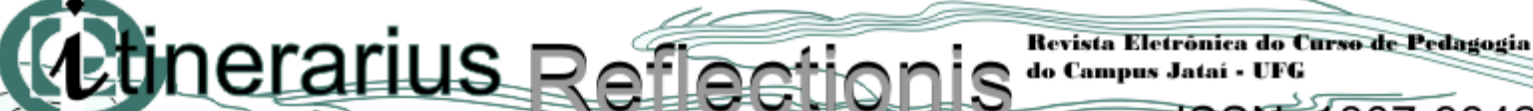 20 更 \\ vol. $2-$ n. $13-2012$

Quando o objetivo é diminuir o impacto gerado pelo lixo, deve-se sempre pensar em reduzir, reutilizar e reciclar. Reduzir o desperdício, reutilizar sempre que for possível antes de jogar fora e reciclar os materiais. Quando falamos em reduzir, a atuação pode começar desde o momento da compra.

De acordo com Carvalho (1998), conhecer o que pensam os alunos sobre meio ambiente e educação ambiental tem sido apontado pela literatura como uma estratégia de fundamental importância para se direcionarem ações e propostas a um programa de educação ambiental.

Nesse contexto, a educação ambiental pode ser uma ferramenta na mudança de mentalidades e de atitudes na relação homem-ambiente. Segundo Marques (1993), um trabalho de educação ambiental será mais rico se tiver como base um levantamento das formas de percepção do ambiente. Sendo assim, faz-se necessário conhecer a visão que o outro tem, tanto do seu lugar, como do espaço antes de se realizar qualquer trabalho que aborde a EA.

O principal objetivo desse trabalho foi diagnosticar a concepção ambiental dos alunos dos cursos integrados que cursam os primeiros anos de eletrotécnica e edificações no Campus Jataí do Instituto Federal de Goiás, possibilitando intervenções partindo da realidade do público alvo.

\section{Metodologia}

No período de agosto de 2011 até junho de 2012, foi realizada a pesquisa no Campus Jataí do Instituto Federal de Goiás, onde o objeto de estudo foram alunos dos primeiros anos dos cursos integrados de eletrotécnica (ET) e edificações (ED), totalizando 75 alunos participantes, destes, 40 cursam ET e 35 ED. A pesquisa foi realizada em três etapas. $\mathrm{Na}$ primeira foi aplicado um questionário semi-estruturado contendo dezessete questões abordando temas ambientais, destas, onze eram objetivas e seis subjetivas. Em seguida, ministrou-se uma palestra envolvendo temática ambiental, visando suprir as deficiências 
conceituais a respeito do tema objeto do estudo. Posteriormente, foi realizada uma oficina com os alunos, no viveiro da própria instituição, onde são produzidas mudas nativas do cerrado reutilizando copos descartáveis, para que tivessem contato direto com projetos de intervenção ambiental a partir de conceitos trabalhados em sala de aula, participando ativamente das diversas etapas de produção de mudas.

\section{Resultados e discussões}

Como citado anteriormente, foram aplicadas 17 questões, neste trabalho será analisado apenas a percepção ambiental, confrontando as respostas objetivas com as questões confirmativas. Não foi analisado a influência do grau de escolaridade dos pais e nem idade ou sexo dos alunos como fator de interferência. Quando questionados os alunos sobre o que faz parte do meio ambiente, $78 \%$ do curso de ED e $23 \%$ dos alunos do curso de ET responderam que o homem, a flora, fauna, rios, solos, montanhas, sítios e casas, ou seja, tudo que rodeia o ser humano. Esta resposta está de acordo com o conceito integrado de meio ambiente, defendido, dentre outros, por Penteado (2010), onde é mencionada a necessidade em considerar os elementos pertencentes aos reinos minerais, animais e vegetais como componentes do meio ambiente, e estes são todos inter-relacionados, destacando o homem (pertencente ao reino animal) pela capacidade que tem de interferir em todos os elementos, alterando-os, consciente e ou inconscientemente através das dimensões econômicas e políticas das organizações sociais que constroem. Os demais alunos (22\% e $77 \%$ dos cursos de ED e de ET, respectivamente) responderam ser o espaço compartilhado entre todos os seres vivos, tudo que se encontra na natureza e que não foi alterado pelo homem, é o espaço como exemplo, montanhas, ar, florestas, oceanos, etc., evidenciando a percepção do meio ambiente como algo separado do ser humano. Através dessa ideia, o meio ambiente é constituído apenas como natural. Uma ideia mais biológica, voltada para ecossistema (FIGUEIREDO, NETO 2003). 


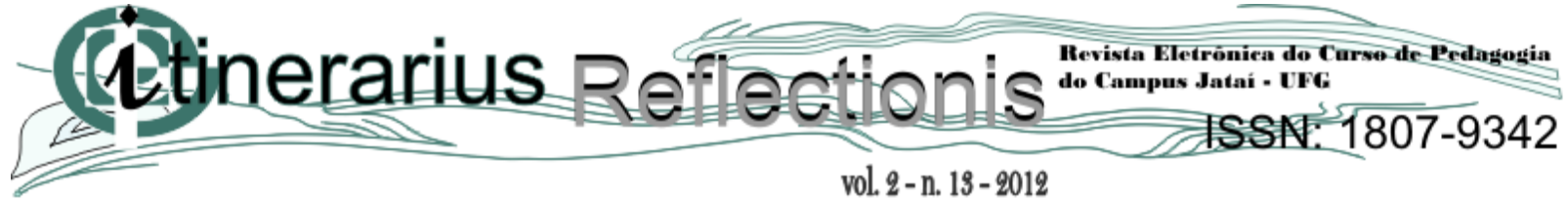

Segundo Travassos (2004), é necessário desenvolver nas escolas o hábito de entender o ambiente como um todo, não fragmentado; aquele criado pelo homem, onde vivemos e o natural, selvagem, o qual devemos preservar ou usar para fazer turismo.

Outra questão abordada foi onde os alunos costumam obter informações a respeito do meio ambiente. Na turma de ED 28\% dos alunos afirmaram, serem os professores os que mais informam sobre meio ambiente, $20 \%$ pela internet, $19 \%$ através de jornais e $9 \%, 8 \%$, $8 \%$, 8\% sendo respectivamente família, livros, revistas televisão. Na turma de ET, responderam que $25 \%$ são através dos professores, $23 \%$ televisão, $19 \%$ internet, $10 \%$ família, $8 \%, 8 \%$ e $7 \%$ respectivamente, livros, revistas e jornais.

Situação intrigante se apresenta na análise dos resultados apresentada pelas duas turmas, pois as duas afirmam, que, preponderantemente através dos professores eles obtém informações sobre o meio ambiente. Referente à primeira questão abordada houve uma divergência nos resultados apresentados, onde na turma ED a maioria possuem uma visão muito diferente do que a turma de ET apresentou sobre o que faz parte do meio ambiente. De acordo com Travassos (2004), as práticas pedagógicas ainda são configuradas segundo um modelo cartesiano e as limitações que esse modelo impõe na sala de aula são muito marcantes, em conseqüência disso, persiste a dificuldade de compreensão das questões ambientais, sob um olhar mais holístico e prático na área da educação. Pela própria natureza epistemológica, os estudos ambientais não podem ser enfocados de outra maneira que não seja global, sob pena de se tornarem segmentados, mal entendidos e pouco abrangentes. Uma visão da educação para o ambiente mais ampla deve envolver as pessoas da comunidade, os currículos escolares e a preparação dos professores em geral, não apenas aqueles que estão ligados às áreas das ciências biológicas ou da geografia.

Em outra questão, foi pedido para que os alunos definissem educação ambiental. Na turma de ED 56\% responderam que é uma educação que visa conscientizar o homem no seu interior para agir de forma diferente diante de questões ambientais, $44 \%$ afirmaram que a educação ambiental visa oferecer conhecimentos para preservar a natureza. Na turma de ET $45 \%$ afirmaram que é uma educação para o meio ambiente, $29 \%$ acreditam ser uma educação voltada para a diminuição do lixo produzida nas cidades e $26 \%$ que é um tipo de educação 
para indivíduos buscarem soluções para não poluírem não destruírem matas e cuidar dos animais.

A palavra educação, presente na questão formulada, parece reforçar a ideia de aprendizagem apresentado nas turmas de ED 44\% e 74\% na de ET. Os alunos transportaram a expressão educação "ambiental" para uma ênfase no ensino sobre o meio ambiente. Já os 56\% da turma ED, possuem a visão de transformar o homem em seus conceitos e representações para cuidar do meio ambiente onde vive com responsabilidade e mantendo a qualidade de vida.

Na turma ET 26\% demonstram a ideia que a educação para o meio ambiente passa pela conscientização das pessoas apenas para não poluir e preservar o que é natural. Isto é consequência do poder da mídia que vende uma imagem da participação de pessoas como agentes responsáveis pela reciclagem do lixo, pela coleta seletiva do mesmo, responsáveis em plantar uma árvore no dia mundial do meio ambiente.

As ideias apresentadas pelos alunos evidenciam que a visão da educação ambiental conservacionista está prevalecendo quando deveria ser o contrário, para que o processo se desenvolva e alcance os objetivos certos.

Muitos professores, preocupados com os problemas ambientais, acham que a educação ambiental tem que ser voltada para a formação de uma consciência conservacionista. Uma consciência, portanto, relacionada com aspectos naturalistas, que considera o espaço natural fora do meio urbano. Dessa visão surge a grande maioria das ações educacionais direcionadas, de forma predominantemente, para a defesa do espaço natural de maneira estrita.

No âmbito das escolas é preciso que fique definido como objetivo pedagógico, qual o tipo de educação ambiental deve ser seguido: uma educação conservacionista cujos ensinamentos conduzem ao uso racional dos recursos naturais e a manutenção de um nível ótimo de produtividade dos ecossistemas naturais ou gerenciados pelo homem, ou uma educação voltada para o meio ambiente que implica uma profunda mudança de valores, uma nova visão do mundo, o que ultrapassa bastante o estado conservacionista (TRAVASSOS, 2004). 


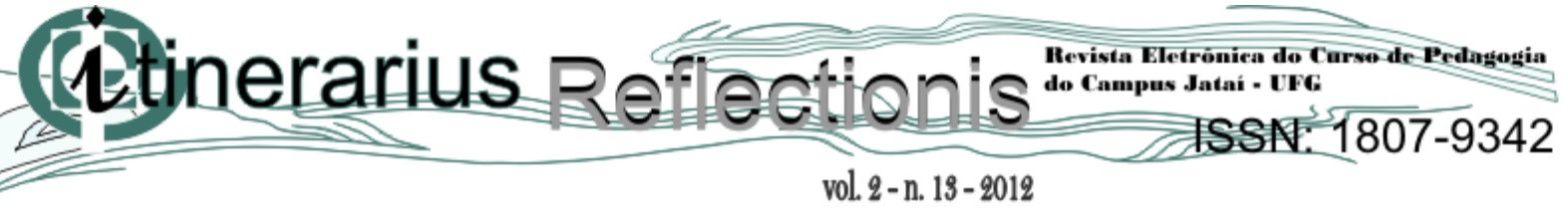

Com relação aos preceitos do PCN / apresentação dos temas transversais, Lobato (1999) afirma que a EA vem sendo considerada uma modalidade educacional e dominada por uma visão técnica, isto é, reduzida ao conservacionismo ou à reciclagem de materiais (oficina de arte). O autor diz ainda que é importante a participação de todas as disciplinas na abordagem dos projetos da prática ambiental.

A EA é um dos eixos fundamentais para impulsionar os processos de prevenção da deterioração ambiental, do aproveitamento dos direitos dos cidadãos a um ambiente saudável. Ela implica uma nova concepção do papel da própria escola. A articulação de seus conceitos, métodos, estratégias e objetivos é complexa e ambiciosa envolvendo dimensões ecológicas, históricas, culturais, sociais, políticas e econômicas da realidade e a construção de uma sociedade baseada em princípios éticos e de solidariedade (COLESANTI, 1996).

\section{Considerações Finais}

A investigação evidenciou que os alunos, de uma forma geral, apresentam ainda uma visão preservacionista e conservacionista sobre o meio ambiente e conceito incipiente sobre educação ambiental. Sabe-se que o termo meio ambiente e educação ambiental estão presentes nos currículos pedagógicos, portanto, é um desafio para professores abordarem e desenvolverem tais termos em sala de aula. Muitos professores possuem dificuldades para ministrar os termos devido ter havido falha na formação acadêmica, outros vêem o tempo como empecilho para trabalhar de forma interdisciplinar.

Segundo Cascino (1999), a reforma do ensino, com as novas diretrizes curriculares e a consequente liberdade dada às escolas, requer o preparo do professor, principalmente para trabalhar interdisciplinaridade e, o que vem acontecendo, é que as escolas estão implantando a nova legislação sem essa preparação.

O professor preparado para exercer sua função dentro da nova visão será um novo professor, mediador do conhecimento, sensível e crítico, aprendiz permanente e organizador do trabalho na escola, um orientador, um cooperador, curioso e, sobretudo, construtor de 


\section{Atherarius Refifectionis \\ vol. 2-n. 13-2012

sentido, pois ensinar não é transferir conhecimento, mas criar possibilidades para a sua produção ou a construção (GADOTTI, 1998).

Fica evidente, a necessidade de preparação e conscientização de professores que possuem dificuldades para abordarem assuntos relacionados sobre educação ambiental, pois, somente assim, conseguirá desenvolver e atuar com um conceito mais holístico de meio ambiente para os alunos. Pois estes representam aqui as gerações futuras em formação, supõese que nelas a consciência ambiental pode ser internalizada e traduzida em comportamento de forma mais bem sucedida, consequentemente, levando a um repertório de hábitos e comportamentos cristalizados de difícil reorientação. E mostrar também que a educação ambiental vai muito além do conservacionismo, trata-se de mudança radical de mentalidade em relação à qualidade de vida, e que está ligada diretamente ao tipo de convivência que o ser humano mantém com a natureza e que implica atitudes, valores, ações etc. Essa conscientização para mudanças na mentalidade e na atitude dos alunos deve começar focalizando não só a natureza, mas o ambiente da escola.

\section{REFERÊNCIAS}

BARBOSA, J. H. Educação Ambiental: movimentos interpretações socioambientais, Lavras: UFLA/FAEPE, 2002.

BRASIL. Ministério da Educação. Parâmetros Curriculares Nacionais para o Ensino Fundamental. v. 9, Brasília-DF, 2001.

CASCINO; F. Educação ambiental. São Paulo: Senac, 1999.

CASTRO; V. O. Educação ambiental Formal e Informal. Monografia, Bacharel em direito na Universidade do Brasil - Canoas, 2004.

CARVALHO, J. C. M. Em direção ao mundo da vida: interdisciplinaridade e educação ambiental. São Paulo: Sema \& Ipê, 1998. 102pp.

COLESANTI; M. Paisagem e educação ambiental. In: Encontro Interdisciplinar sobre o Estudo da Paisagem, 3. Rio Claro: UNESP, 1996. p.35. 


\section{Etinerarius Re $\Delta$}

DIAS, G. F. Educação Ambiental: princípios e práticas. São Paulo, Gaia, 1992.

DIAS, G. F. Educação e Gestão ambiental. São Paulo, Gaia, 2006.

FIGUEIREDO, J.; NETO, G. G.. Aspectos da percepção ambiental de um grupo de empresários de Sinop, Mato Grosso, Brasil. Monografia de conclusão de curso de Graduação em Biologia UFMT. Revista Eletrônica do Mestrado em Educação ambiental. Cuiabá, 2003. Disponível em <htpp://www.remea.furg.br/edicoes/vol22/art2v22.pdf. Acesso em maio de 2012.

GADOTTI; M. Pedagogia da Práxis. São Paulo: Cortez, 1998.

LOBATO; W. Educação e meio ambiente: O desafio da incorporação da dimensão ambiental na prática docente. In: Encontro Nacional de Prática de ensino de Geografia, 5, 1999, Belo Horizonte. Anais... Pontifícia Universidade Católica de Minas Gerais, 1999, p. 75.

LOPES, J. M; NETO,J.F.G.; SANTOS, I. A. A educação ambiental trabalhada no ensino médio no contexto da lei 394/96. Disponível em <htpp://www.deminarioicues.com.br/sistema/resumos/2007.89.pdf. Acesso em junho de 2012.

MARCATTO, C. Educação ambiental: conceitos e princípios Belo Horizonte: FEAM, 2006.

MARQUES, J. G. W. Etnoecologia, educação ambiental e superação da pobreza em áreas de manguezais. Anais do $1^{\circ}$ Encontro Nacional de Educação Ambiental em Áreas de Manguezais, 1993. Maragogipe, Brasil, p. 29-35.

OLIVEIRA, N, F.; Barcelos, V. H. L. Educação ambiental e cidadania: cenários brasileiros. Santa Cruz do Sul: EDUNISC, 2003.

PENTEADO, H. D.; Meio ambiente e formação de professores. 7. ed. São Paulo: Cortez, 2010.

RUY, R. A.V. A educação ambiental na escola. Revista eletrônica do Mestrado de educação ambiental, Unesp de Rio Claro, n. 26, maio 2004. Disponível em <http://www.periodicos.rc.biblioteca.unesp.br/Acesso em junho de 2012.

SAHED, D.; ASIMELLI-LUZ, A. As representações de meio ambiente de professores e alunos e a pedagogia de projetos: um estudo de caso em classes de alfabetização. In: Revista Eletrônica do Mestrado em Educação Ambiental, Unesp de Rio Claro, v. 16, junho 2006, 17p. Disponível em<http: www.seer.furg.br/remea/article/view/2817/1577. Acesso em maio de 2012. 
SALEM. P. S. Informativo do Instituto Ecológico, n. 62, agosto/setembro,2005. Disponível em <http://www.institutoaqualung.com.brinfo_planeta_terra_62html>. Acesso em 5 de setembro 2012.

SATO, M. Tele - Educación ambiental: construyendo utopias. Tópicos en Educación Ambiental. 2000.

SOUZA, A. K. A relação escola-comunidade e a conservação ambiental. Monografia. João Pessoa: Universidade Federal da Paraíba, 2000.

TRAVASSOS, E. A prática da Educação Ambiental nas escolas. Porto Alegre-RS: Mediação, 2004.

VASCONCELOS, H. S. R. A pesquisa-ação em projetos de Educação Ambiental. In: Guadalara, v. 2, n. 4, p. 41- 48, 2000. 